\title{
Sintering behaviour and interfacial toughness of HAp/TCP coatings on HAp/Ti nanocomposite substrates
}

\author{
M J RASTGOO, M RAZAVI*(D, E SALAHI and I MOBASHERPOUR \\ Materials and Energy Research Center (MERC), P.O. Box 14155-4777, Tehran, Iran \\ *Author for correspondence (m-razavi@merc.ac.ir)
}

MS received 3 February 2018; accepted 3 May 2018; published online 17 January 2019

\begin{abstract}
Spark plasma sintering (SPS) is used in rapid compaction of materials in order to achieve higher compact density and in improving mechanical strength and toughness. However, implants produced by SPS do not have preferred positions for formation of a bone-like apatite layer on their surface due to their high density. Biphasic-calcium phosphate (BCP) ceramics consisting of stable hydroxyapatite (HAp) and soluble tri-calcium phosphate (TCP) are developed to achieve a controllable biodegradation rate and biological stability by adjusting the TCP/HAp ratio. The primary goal of this study is to improve mechanical properties and bioactivity of implants. HAp/20 wt $\%$ Ti nanocomposite powders were chosen for bulk, and also HAp/TCP nanocomposite powders were chosen for coatings with weight percentages of 75/25, 50/50 and 25/75, respectively. The samples were sintered for $5 \mathrm{~min}$ at a compaction pressure of $30 \mathrm{MPa}$ and at different temperatures of 650 and $750^{\circ} \mathrm{C}$. The phase changes of the coatings are studied by X-ray diffraction. Mechanical properties such as interfacial toughness are investigated. The results show that amount of TCP increases with increasing sintering temperature in HAp/ 75 wt\% TCP coating, however no significant change was observed in amount of TCP in HAp/25 wt\% TCP coating. Also, the maximum value of interfacial toughness is equal to $34 \mathrm{MPa} \mathrm{mm}{ }^{1 / 2}$, which was obtained for $75 \mathrm{wt} \% \mathrm{HAp}-25 \mathrm{wt} \% \mathrm{TCP}$ coating sintered at $750^{\circ} \mathrm{C}$.
\end{abstract}

Keywords. Hydroxyapatite-titanium nano-composite; SPS; mechanical properties.

\section{Introduction}

Calcium phosphate-based bioceramics show excellent biocompatibility and are osteoconductive, allowing bone cells to grow on their surface. For this reason, they have been used successfully in dentistry and orthopaedics for many years [1]. Among these bioceramics, particular attention has been paid to hydroxyapatite $\left[\mathrm{Ca}_{10}\left(\mathrm{PO}_{4}\right)_{6}(\mathrm{OH})_{2}\right.$, HAp] and tri-calcium phosphate $\left[\mathrm{Ca}_{3}\left(\mathrm{PO}_{4}\right)_{2}, \mathrm{TCP}\right]$ due to their outstanding biological responses to physiological environments [1,2]. HAp is stable in a body fluid, whereas TCP is rather soluble in the fluid [3].

Many studies have indicated that if the dissolution of the bone-graft materials in the body fluid is too low, beginning of bone-implant bonding may take a long time, whereas fast dissolution can deteriorate the implant [4,5]. Therefore, it is very important to achieve an optimum dissolution rate of implant for stable bone-implant bonding. It is well-known that biphasic-calcium phosphate (BCP) ceramics consisting of a mixture of HAp and TCP have been widely used as bone substitutes, and have a controllable dissolution rate to the HAp/TCP ratio $[6,7]$.

Adhesion of a coating on its substrate is an important factor to be considered for the use of the coatings during loadbearing situation [8]. Among the various methods to evaluate the adhesion of coatings on substrates, the most common is a standard tensile adhesion test (ASTM standard C633-79) [9]. It is believed that the tensile adhesion test has some deficiencies such as the used bonding agent has a limited strength resistance, dependence of coating failure to the flaw distribution at the specimen edge and a possibility of penetration of the used glue into the coating [10].

One of the methods that is used to overcome these limitations is an interfacial indentation test. This method uses an indentation test to generate and propagate a crack at the interface. On the other hand, Vickers indentation is performed over the polished cross-section of the coated sample and the adhesion of coatings to their substrates could be successfully evaluated with the apparent fracture toughness. The advantages of this methodology include easy to perform and no adhesive glue is needed. Also, its limitations are the problems of measuring the crack length and the thickness of the coating that should be larger than $100-150 \mu \mathrm{m}$ to avoid cracking within the coating [11-13].

In the present study, BCP coatings were achieved with different HAp/TCP ratios on an $80 \mathrm{wt} \% \mathrm{HAp}-20 \mathrm{wt} \% \mathrm{Ti}$ nanocomposite substrate by spark plasma sintering (SPS). The phase evolution and phase changes of powders and coatings were studied by X-ray diffraction (XRD) and Fourier-transform infrared (FTIR) techniques. Adhesive of the coatings was evaluated by using Vickers indentation methods. 


\section{Experimental}

\subsection{Materials}

HAp and TCP powders used in this study were synthesized by a solution route using calcium nitrate tetrahydrate (Merck, code no. 1.02121) as a $\mathrm{Ca}^{2+}$ source and ammonium dihydrogen phosphate (Merck, code no. 1.01207) as a $\mathrm{PO}_{4}^{3-}$ source. The initial $\mathrm{Ca} / \mathrm{P}$ ratios were equal to 1.67 for the synthesized HAp and equal to 1.5 for the synthesized TCP. Each of the raw materials was dissolved in $250 \mathrm{ml}$ distilled water separately and $\mathrm{pH}$ values of the solutions were maintained at $\sim 11$ for HAp and $\sim 10$ for TCP during precipitation by adding ammonium. An ammonium phosphate solution was added to a stirred calcium nitrate solution drop by drop. The precipitate was washed, dried at $50^{\circ} \mathrm{C}$ for $48 \mathrm{~h}$ and crushed into precursor powder. Then HAp and TCP powders were calcined at 900 and $1200^{\circ} \mathrm{C}$ for $1 \mathrm{~h}$ in air, respectively.

The HAp powder was mixed with $20 \mathrm{wt} \%$ pure titanium (Merck, code no. 1.12379) powders for obtaining nanocomposite substrates. The HAp/Ti mixture was prepared in a planetary ball mill (RETSCH-PM400, Germany). Milling was carried out using stainless steel balls at the speed of $300 \mathrm{rpm}$, and with a constant ball to powder ratio of 10:1 at room temperature under an $\mathrm{Ar}$ atmosphere. The reasons for selection of this situation are published in an earlier work [14]. Coating powders of varying HAp/TCP weight ratios (25/75, $50 / 50$ and $75 / 25$ ) were obtained by a simple dry mixing of HAp and TCP powders in a glass vessel.

The HAp/TCP and HAp/Ti powders were placed inside a steel cylindrical mould separately, and compacted into billets of $d=30 \mathrm{~mm}$ at a pressure of $600 \mathrm{MPa}$.

Compacted HAp/Ti powders were placed between two layers of compacted powders HAp/TCP and they were loaded into a graphite mould with an inner diameter of $30 \mathrm{~mm}$ and then sintering was carried out in an SPS apparatus (Easy Fashion, China) at 650 and $750^{\circ} \mathrm{C}$ under the pressure of $30 \mathrm{MPa}$ and in the vacuum of $15 \mathrm{~Pa}$. After maintaining at the desired temperature for $5 \mathrm{~min}$, samples were cooled in the vacuum chamber and then were removed from the mould.

\subsection{Characterization}

An FTIR spectrometer (PerkinElmer, RX1) was employed to analyse the chemical groups present in the synthesized HAp and TCP.

An X-ray diffractometer system (Siemens, D500, Germany) was used to analyse the phase structure of the synthesized powders and the coatings under ambient conditions and the radiation source was $\mathrm{Cu}-\mathrm{K} \alpha$. The peaks obtained were compared with standard reference JCPDS files by using X'Pert software.

\subsection{Mechanical properties}

The interfacial indentation test was performed at the interface of HAp/20 wt $\%$ Ti substrates and HAp/TCP coatings.

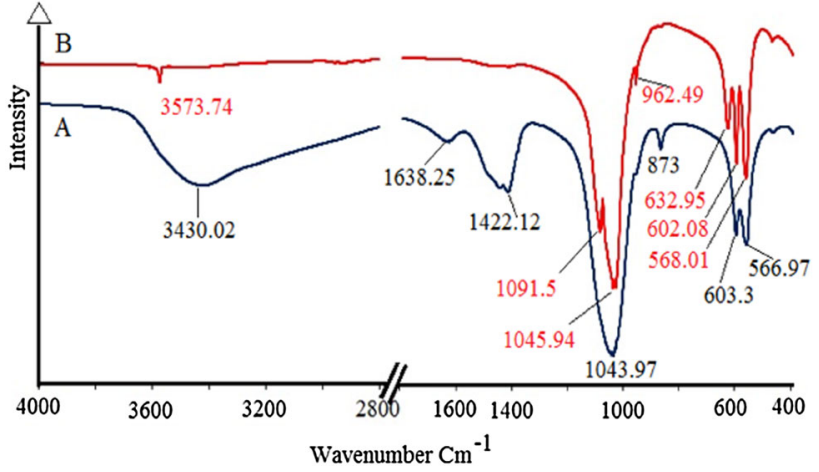

Figure 1. FTIR spectra of the synthesized HAp: (A) before calcination and (B) after calcination at $900^{\circ} \mathrm{C}$ for $1 \mathrm{~h}$ in air.

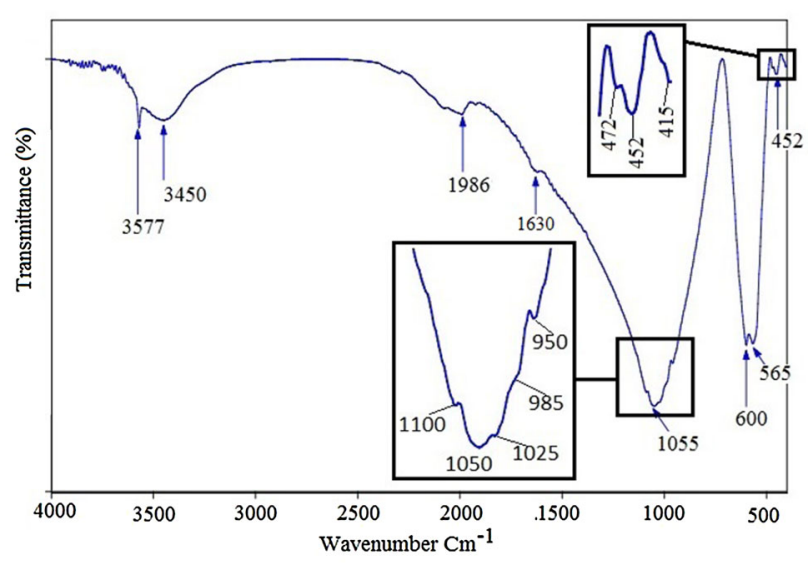

Figure 2. FTIR spectra of the synthesized TCP.

In the first step, the cross-section of the coated samples was polished and then the indentation test was performed using a Vickers diamond pyramid with a $10 \mathrm{~N}$ contact load by a Vickers hardness tester (Koopa, UV1, Iran). The crack length was measured along the interface of the substrate and coating. Cracks formed at each of the corners of the indent in the interface were considered as separate cracks. The cracks, which insert into the coating, were not considered for calculations. More than 12 crack lengths were measured for each sample. The following equation was used to calculate the relative fracture toughness $\left(K_{\mathrm{c}}\right)$ of the interface $[11,12,15]$ :

$$
K_{\mathrm{c}}=0.079\left(\frac{P}{a^{3 / 2}}\right) \log \left(4.5 \frac{a}{c}\right)
$$

where $K_{\mathrm{c}}$ is the interfacial fracture toughness $\left(\mathrm{MPa} \mathrm{mm} \mathrm{m}^{1 / 2}\right.$ ), $P$ is the applied load $(\mathrm{N}), a$ is the half-indent diagonal length $(\mathrm{mm})$ and $c$ is the crack length from the centre of the indent to crack edge $(\mathrm{mm})$. The recommended $c / a$ ratio for this model is $0.65<c / a<4.5$ [15]. 


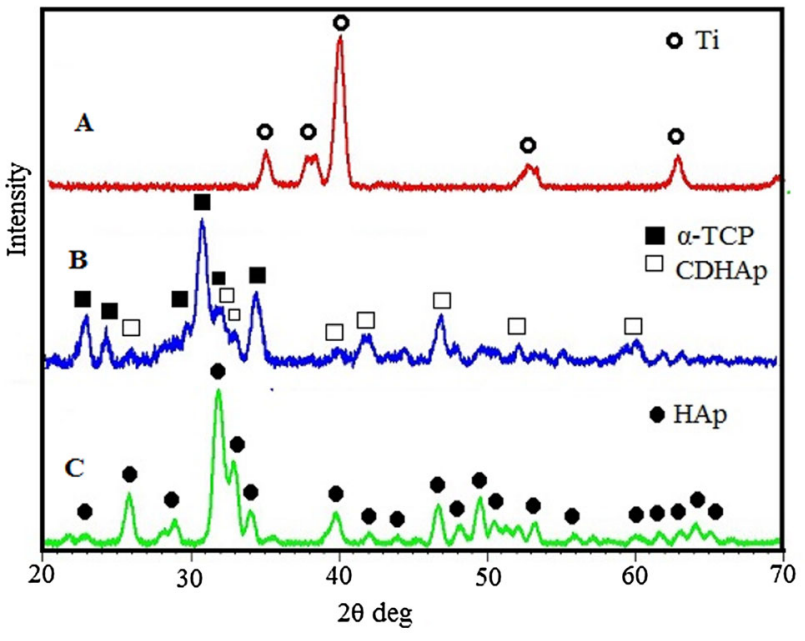

Figure 3. XRD spectra of (A) titanium, (B) the synthesized TCP after calcination at $1200^{\circ} \mathrm{C}$ for $1 \mathrm{~h}$ in air and (C) the synthesized HAp after calcination at $900^{\circ} \mathrm{C}$ for $1 \mathrm{~h}$ in air.

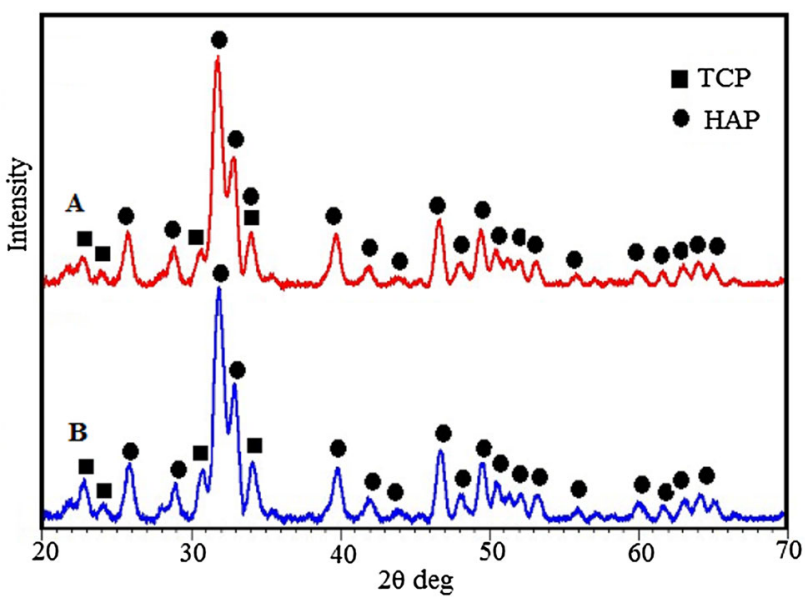

Figure 4. XRD pattern of HAp-25\% TCP: (A) sintering at $750^{\circ} \mathrm{C}$ and (B) sintering at $650^{\circ} \mathrm{C}$.

Due to the scatter of the results, it is not reasonable to report the average. For this reason, the calculated data were analysed according to a statistical way, Weibull plot $[12,16]$. First, the results were arranged descending. Then the value of $W$ was calculated using the following equation:

$$
W=\frac{n}{N+1},
$$

where $n$ is the number of measurement points and $N$ is the total number of measurement points. The measured $K_{\mathrm{c}}$ and $W$ were then analysed by using a simple least-squares regression method, according to the alternative form of two-parameter Weibull distribution equation.

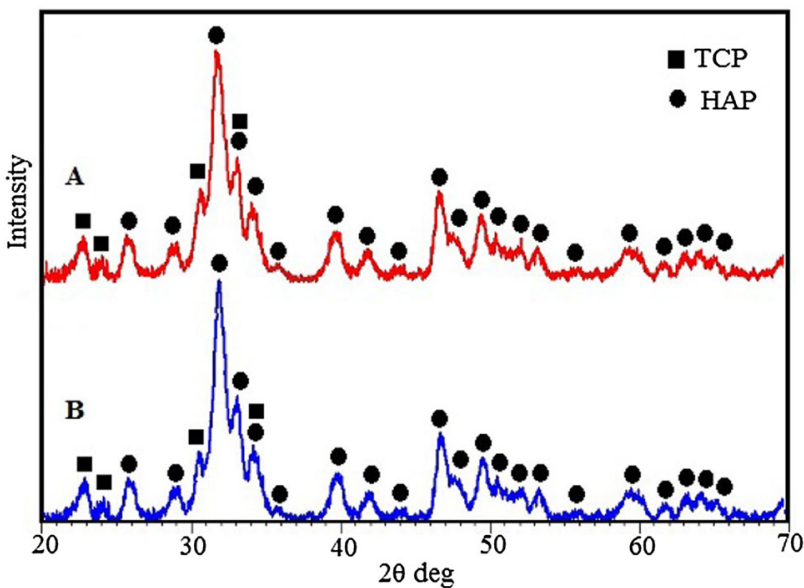

Figure 5. XRD pattern of $\mathrm{HAp}-50 \% \mathrm{TCP}$ : (A) sintering at $750^{\circ} \mathrm{C}$ and (B) sintering at $650^{\circ} \mathrm{C}$.

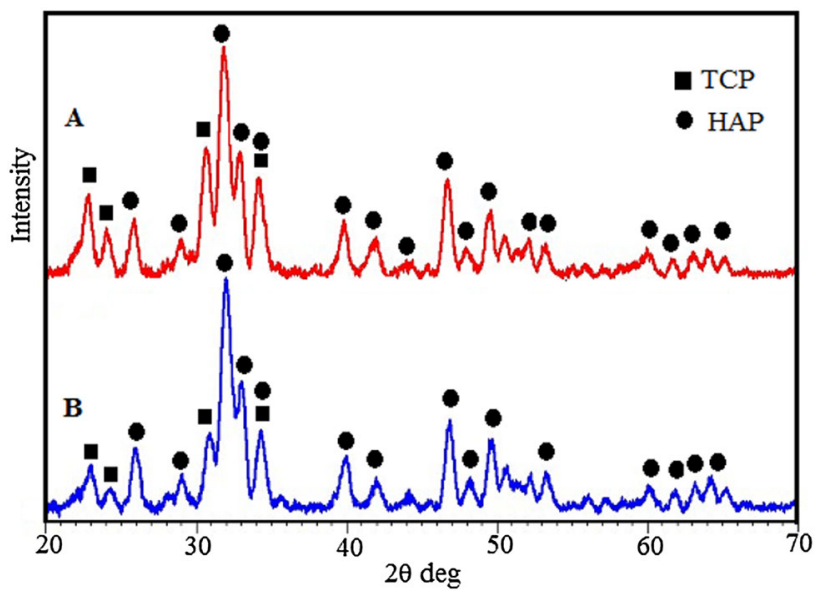

Figure 6. XRD pattern of HAp-75\% TCP: (A) sintering at $750^{\circ} \mathrm{C}$ and (B) sintering at $650^{\circ} \mathrm{C}$.

\section{Results and discussion}

\subsection{Powder characterization}

FTIR spectra of the synthesized HAp before and after calcination are shown in figure 1 . As stated in the previous work [14], in the case of calcined HAp, the two sharp peaks observed at 3573 and $632 \mathrm{~cm}^{-1}$ are due to the characteristic stretching and vibrational modes of the structural OH groups $[17,18]$. The double peaks at 602 and $568 \mathrm{~cm}^{-1}$ belongs to the $\mathrm{PO}_{4} v_{4}$ mode, $962 \mathrm{~cm}^{-1}$ to the $\mathrm{PO}_{4} v_{1}$ mode and the peaks at 1091 and $1045 \mathrm{~cm}^{-1}$ to the $\mathrm{PO}_{4} \nu_{3}$ mode $[19,20]$. Also, in the case of HAp before calcination, in addition to the above-mentioned bands, the bands at 1638 and $873 \mathrm{~cm}^{-1}$ are attributed to some carbonate contents, the band at $1422 \mathrm{~cm}^{-1}$ is attributed to the presence of the $\mathrm{NH}_{4}^{+}$group [20] and the broad absorption band at $3430 \mathrm{~cm}^{-1}$ is due to the $\mathrm{O}-\mathrm{H}$ stretching vibration of the hydrogen bonded $\mathrm{OH}$ 

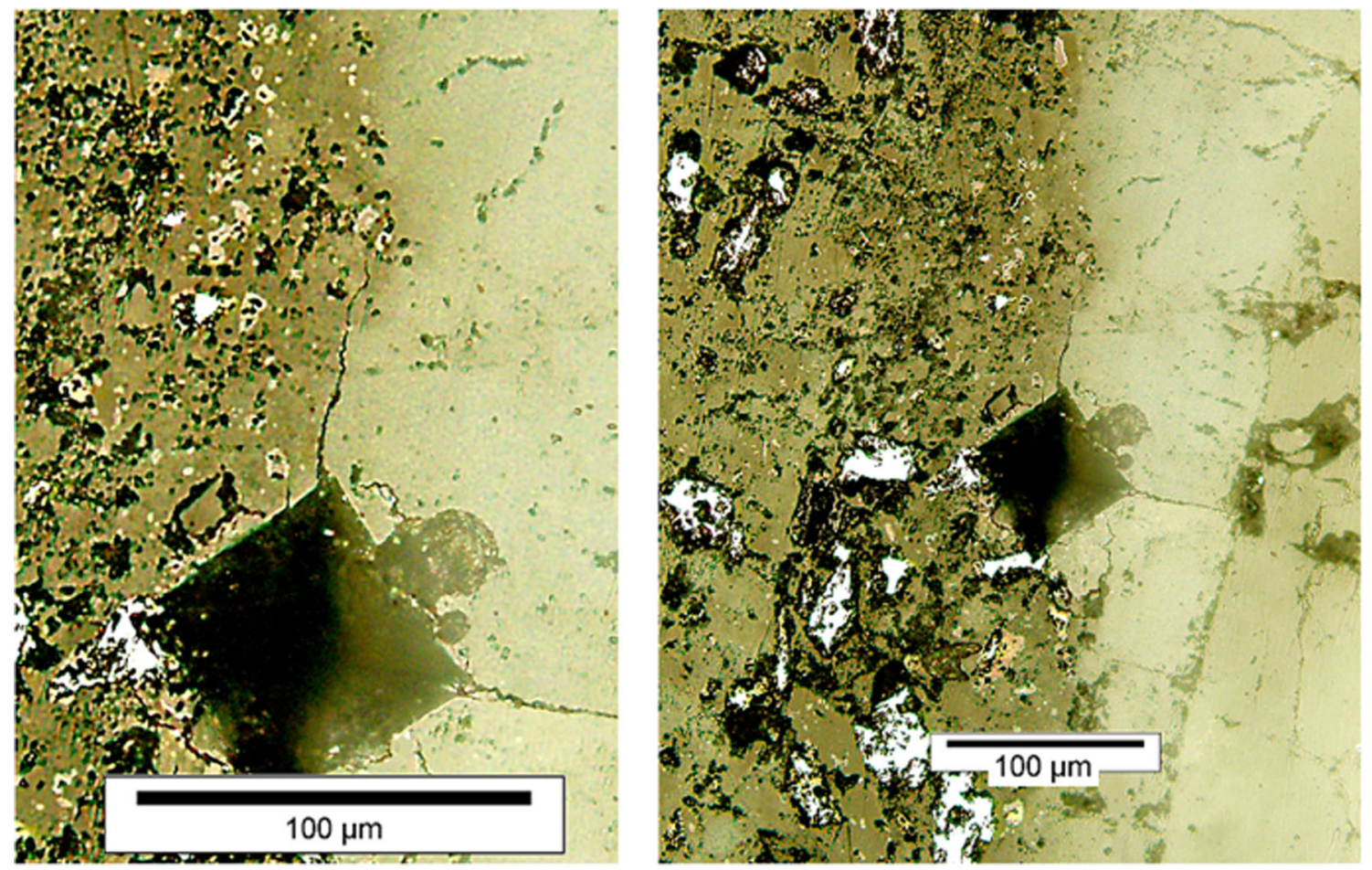

Figure 7. Images of indentation and crack propagation at the interface of coating and substrate for the HAp-50\% TCP coating sintered at $750^{\circ} \mathrm{C}$ at two magnifications.

groups, are evidence of the presence of absorbed water in the synthesized HAp that all of them disappeared after calcination at $900^{\circ} \mathrm{C}[17,18]$. Therefore, according to these explanations, it is obvious that the synthesized powder is certainly HAp.

The FTIR spectra of the synthesized TCP are shown in figure 2. The main absorption bands and their characteristics of FTIR spectra are analysed in the following. There are four vibration modes $(v 1-v 4)$ present for phosphate ions of $\alpha$-tricalcium. One band at $954 \mathrm{~cm}^{-1}$ is discernible corresponding to the symmetric $\mathrm{P}-\mathrm{O}$ stretching vibration $(v 1)$ of $\alpha$-TCP. Also bands present at ca. 985,1025 and $1055 \mathrm{~cm}^{-1}$ are due to the triple-degenerate asymmetric $\mathrm{P}-\mathrm{O}$ stretching mode ( $v 3)$ of $\alpha$-TCP. Weak infrared bands at ca. 415,452 and $472 \mathrm{~cm}^{-1}$ arise due to the symmetric $\mathrm{P}-\mathrm{O}$ bending doubly degenerate (v2) and those at ca. 565 and $600 \mathrm{~cm}^{-1}$ are due to the asymmetric P-O bending triply degenerate $(v 4)$ of $\alpha$-TCP [21]. In addition, the weak band at $1638 \mathrm{~cm}^{-1}$ is attributed to the presence of some carbonate contents [20].

The band at $1986 \mathrm{~cm}^{-1}$ is possibly due to the $\mathrm{P}-\mathrm{O}(\mathrm{H})$ stretching in the $\mathrm{HPO}_{4}^{2-}$ groups, which is characteristic of calcium deficient apatite (CDHAp) [22]. The broad absorption band at $3450 \mathrm{~cm}^{-1}$ assigned to the $\mathrm{O}-\mathrm{H}$ stretching vibration mode is evidence of the presence of absorbed water and the sharp peak observed at $3573 \mathrm{~cm}^{-1}$ is due to the characteristic stretching and vibrational modes of the structural $\mathrm{OH}$ groups for CDHAp [17]. Therefore, according to these explanations, it is obvious that the synthesized powder is $\alpha$-TCP and CDHAp.

The XRD analyses of HAp, TCP and Ti powders are shown in figure 3. Peaks labelled correspond to HAp [JCPDS file no. 074-0565], $\alpha$-TCP [JCPDS file no. 0290359], \{CDHAp, $\left.\mathrm{Ca}_{9}\left(\mathrm{HPO}_{4}\right)\left(\mathrm{PO}_{4}\right)_{5}(\mathrm{OH})\right\}$ [JCPDS file no. 046-0905] and Ti [JCPDS file no. 089-3073].

\subsection{Phase evaluation of coating}

Figures 4-6 show the XRD pattern of coatings of the HAp$(25,50,75) \%$ TCP sintered at 650 and $750^{\circ} \mathrm{C}$ temperatures by SPS. It suggests that amount of TCP increases with increasing sintering temperature in HAp-75\% TCP, however no significant change is observed in the amount of TCP in HAp- $25 \%$ TCP. Also, the amount of TCP increased very slightly by increasing the sintering temperature from 650 to $750^{\circ} \mathrm{C}$ in HAp-50\% TCP.

These results reveal that in addition to sintering temperature, the phase composition of coatings depends on the starting TCP concentration. This is also expressed in other researchers' reported results [23,24]. The formula expressed in equation (2) can be used to show the decomposition of HAp [23]:

$$
\mathrm{Ca}_{10}\left(\mathrm{PO}_{4}\right)_{6}(\mathrm{OH})_{2} \rightarrow 3 \mathrm{Ca}_{3}\left(\mathrm{PO}_{4}\right)_{2}+\mathrm{CaO}+\mathrm{H}_{2} \mathrm{O} \uparrow
$$


The progression of the HAp decomposition reaction needs the activation of two stages, including nucleation of the phases of the products and the elimination of gaseous reaction products. It seems that the interfaces between HAp and TCP, which contain more defects than the single-phase HAp boundaries, are preferable for nucleation of product phases, and thus accelerate nucleation. Also, these interfacial areas between HAp and TCP are effective routes to eliminate gaseous products. There are most interfacial areas between HAp and TCP particles in the coating containing $75 \mathrm{wt} \%$ TCP. Consequently, in view of the above, the HAp decomposition reaction is facilitated by the presence of high-TCP content in the coating containing $75 \mathrm{wt} \% \mathrm{TCP}$ and the TCP phase in this coating increases with an increase in the sintering temperature from 650 to $750^{\circ} \mathrm{C}$.

\subsection{Interfacial indentation test}

For instance, figure 7 shows images of indentation and crack propagation in the interface of coating and substrate for the $\mathrm{HAp}-50 \%$ TCP coating sintered at $750^{\circ} \mathrm{C}$ at two magnifications. Figure 8A and B shows Weibull distribution curves for the HAp- $(25,50,75) \%$ TCP coatings sintered at 650 and $750^{\circ} \mathrm{C}$. Also, figure 9 shows interfacial toughness obtained from figure 8 . It is found that interfacial toughness of all coatings with a constant HAp content is increased by increasing the sintering temperature from 650 to $750^{\circ} \mathrm{C}$. Also interfacial toughness will be increased with increasing HAp content of coatings sintered at both of 650 and $750^{\circ} \mathrm{C}$ temperatures.

The adhesion strength of a coating to a substrate can be a function of variables such as the thermal and elastic mismatches between the coating and the substrate, and the presence of defects at or near the interface $[25,26]$. It seems that when initial content for coatings is constant, increasing the sintering temperature increases the density of the coating and decreases the porosity in the coating, which increases the adhesion of the coatings. Also, due to the composition of the substrate containing $80 \mathrm{wt} \% \mathrm{HAp}$, increasing the percentage of HAp in the coating reduces the thermal and elastic mismatches between the coating and the substrate and causes increasing of adhesion of coating. Also, a slight increase of adhesion by raising sintering temperature in $25 \mathrm{wt} \% \mathrm{HAp}$ coatings testifies this issue. Because, as already mentioned, raising sintering temperature increases the TCP content of coating and causes an increasing of mismatches. The raising of thermal and elastic mismatches between the coating and the substrate decreases the effects of increasing density and reduces the defects in the interfacial area. Also, the effect of temperature seems to be the most prominent in the case of HAp-50\% TCP compared with HAp- $(25,75) \%$ TCP and adhesion strength shows a larger increase with increasing sintering temperature. TCP has a lower sinterability than HAp [27], hence it seems that compared with HAp-75\% TCP, the lower TCP in HAp-50\% TCP causes a higher increase in density and less defects as the sintering temperature rises. Also, the effect of mismatches caused by higher HAp in HAp-50\%
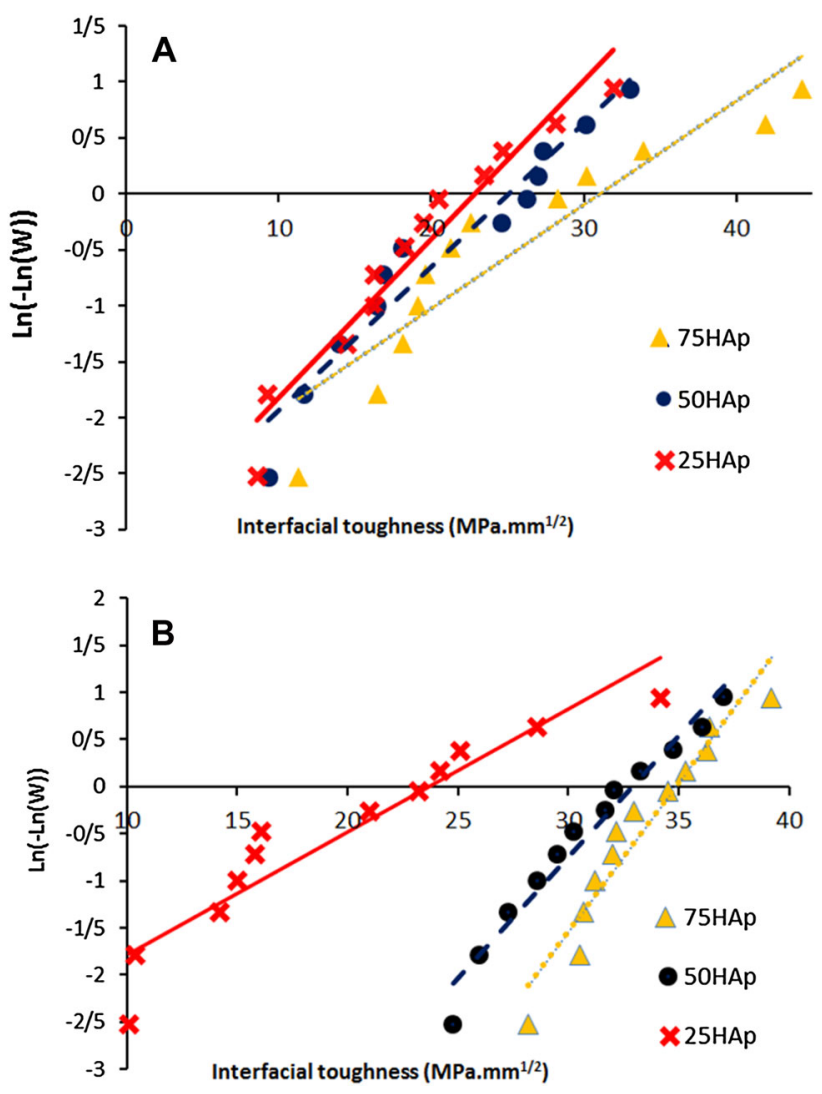

Figure 8. Weibull distribution curves for the HAp- $(25,50,75) \%$ TCP coatings: (A) sintered at $650^{\circ} \mathrm{C}$ and $(\mathbf{B})$ sintered at $750^{\circ} \mathrm{C}$.

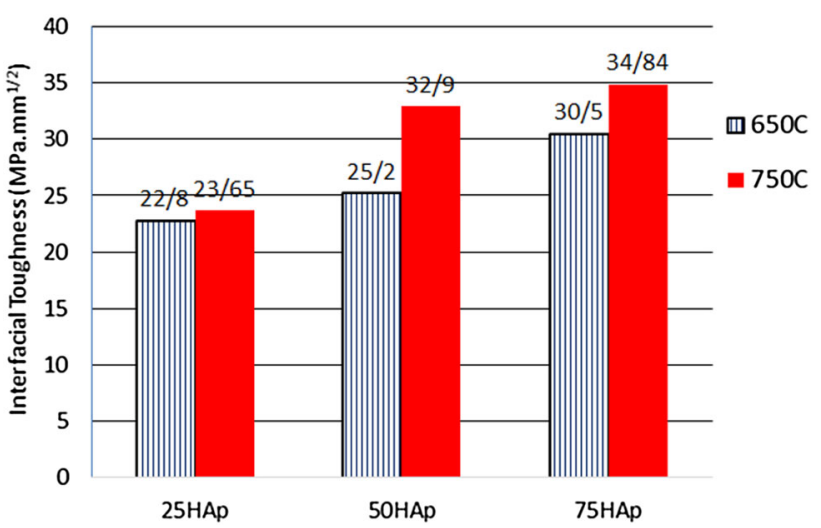

Figure 9. Interfacial toughness for the HAp- $(25,50,75) \%$ TCP coatings.

TCP coating is less compared with HAp-75\% TCP, which shows both of these effects cause higher increase of adhesion strength. While in HAp-25\% TCP, a high percentage of HAp coating is included such that it has high sinterability and a higher density is achieved at low sintering temperatures. Therefore, the rate of increase of density and reduction of defects is reduced with increasing the sintering temperature in HAp-25\% TCP. This causes that increase of adhesion 
strength is less in HAp-25\% TCP compared with HAp-50\% TCP.

\section{Conclusions}

1. Coatings have been successfully prepared with different HAp and TCP contents on HAp-20 wt\% Ti substrates by SPS.

2. Amount of TCP increases with rising sintering temperature for coatings with $75 \mathrm{wt} \% \mathrm{TCP}$, however no significant change is observed in the amount of TCP for coatings with $25 \mathrm{wt} \%$ TCP.

3. The maximum value of interfacial toughness $\left(34 \mathrm{MPa} \mathrm{mm}{ }^{1 / 2}\right.$ ) is obtained for coating with $75 \mathrm{wt} \%$ HAp-25 wt $\%$ TCP sintered at $750^{\circ} \mathrm{C}$. Increasing the sintering temperature and the content of the HAp in the HAp/TCP coatings will increase the interfacial toughness.

\section{References}

[1] Hench L L and Wilson J 1993 An introduction to bioceramics (Singapore: World Scientific Publishing Co.) i-X

[2] Kwon S H, Jun Y K, Hong S H, Lee I S, Kim H E and Won Y Y 2002 J. Am. Ceram. Soc. 853129

[3] Yang X and Wang Z 1998 J. Mater. Chem. 82233

[4] Sun L, Berndt C C, Gross K A and Kucuk A 2001 J. Biomed. Mater. Res. 58570

[5] Hahn B, Park D, Choi J, Ryu J, Yoon W and Lee B 2009 J. Am. Ceram. Soc. 92793

[6] Liu D M, Troczynski T and Tseng W J 2001 Biomaterials 22 1721

[7] Dorozhkin S V 2012 Acta Biomater. 8963
[8] Marot G, Lesage J, Démarécaux P, Hadad M, Siegmann S and Staia M H 2006 Surf. Coat. Technol. 2012080

[9] ASTM C633-79 2001 Standard test method for adhesion or cohesion strength of thermal spray coatings (West. Conshohocken, PA, USA: ASTM)

[10] Tsui Y C, Doyle C and Clyne T W 1998 Biomaterials 192015

[11] Nusair Khan A, Lu J and Liao H 2003 Mater. Sci. Eng. A 359 129

[12] Sadeghi-Fadaki S A, Zangeneh-Madar K and Valefi Z 2010 Surf. Coat. Technol. 2042136

[13] Mohammadi Z, Ziaei-Moayyed A A and Sheikh-Mehdi Mesgar A 2007 Appl. Surf. Sci. 2534960

[14] Rastgoo M J, Razavi M, Salahil E and Mobasherpour I 2017 J. Aust. Ceram. Soc. $\mathbf{5 3} 1$

[15] Evans A G and Charles E A 1976 Am. Ceram. Soc. 59371

[16] Lugscheider E, Bobzin K, Barwulf S and Etzkorn A 2001 Surf. Coat. Technol. 1389

[17] Barinow S M, Rau J V, Nunziante Cesaro S, Ďurišin J, Fadeeva I V, Ferro D et al 2006 J. Mater. Sci. Mater. Med. 17597

[18] Qian J, Kang Y, Zhang W and Li Z 2008 J. Mater. Sci. Mater. Med. 193373

[19] Pramanik S, Agarwal A K, Rai K N and Garg A 2007 Ceram. Int. 33419

[20] Meejoo S, Maneeprakorn W and Winotai P 2006 Thermochim. Acta 447115

[21] Jillavenkatesa A and Condrate R A 1998 Spectrosc. Lett. 31 1619

[22] Salahi E and Heinrich J G 2003 Br. Ceram. Trans. 10279

[23] Kivrak N and Tas A C 1998 J. Am. Ceram. Soc. 812245

[24] Skorokhod V V, Solonin S M, Dubok V A, Kolomiets L L, Permyakova T V and Shinkaruk A V 2010 Powder Metall. Met. Ceram. 49324

[25] Mellali M, Fauchais P and Grimaud A 1996 Surf. Coat. Technol. 81275

[26] Singh R K, Gilbert D R, Fitz-Gerald J, Harkness S and Lee D J 1996 Science 272393

[27] Jarcho M, Bolen C H, Thomas M B, Bobick J, Kay J F and Doremus T H 1976 J. Mater. Sci. 112027 